\title{
Polimorfismo Pro 72Arg del gen TP53 y enfermedad coronaria
}

\section{Marcela Pizarro, Natalia Torrealba, Roberto Bravo, Leticia González, Sergio Lavandero.}

Centro FONDAP Estudios Moleculares de la Célula, Facultad de Ciencias Químicas y Farmacéuticas / Facultad de Medicina, Universidad de Chile.

Recibido el 14 de octubre de 2009, aceptado el 30 de octubre de 2009

Rev Chil Cardiol 2009; 28: 385-387

La enfermedad de las arterias coronarias se caracteriza por la acumulación de depósitos de grasa en las células que revisten la pared de una arteria coronaria y, en consecuencia, obstruyen el flujo de sangre. Para que el corazón se contraiga y bombee sangre normalmente, requiere una provisión continua de sangre rica en oxígeno. La obstrucción parcial o total de una arteria coronaria lleva al desarrollo de isquemia, originando importantes lesiones en el músculo cardíaco. La causa más frecuente de isquemia del miocardio es la enfermedad de las arterias coronarias.

Aunque la enfermedad de las arterias coronarias afecta a personas de todas las etnias, su incidencia es particularmente elevada entre los blancos. Sin embargo, la etnia en sí misma no parece ser un factor tan importante como el hábito de vida de cada individuo ${ }^{1}$.

La etiología de la enfermedad coronaria ha sido objeto de intenso estudio en las últimas décadas. Factores de riesgo clásicos: sexo, diabetes, hipertensión arterial y la enfermedad renal crónica, niveles anormales de colesterol, tabaquismo, consumo excesivo de alcohol ${ }^{1}$, sólo explican la mitad de los casos, por lo que se están buscando nuevos factores etiológicos en el ámbito de la genética molecular.

En general toda la patología aterosclerótica tiene un componente hereditario importante. La identificación de los genes responsables del aumento del riesgo ha facilitado la detección de cambios deletéreos en la secuencia del DNA.
Se denominan mutaciones o polimorfismos a la coexistencia de variedades o alelos de un mismo gen, el alelo natural o silvestre ("wild type") y el alelo mutante. Sin embargo, suele reservarse el término mutación para aquellos cambios que alteran gravemente la función de la proteína o enzima codificada y basta un gen para provocar una enfermedad. En cambio, se denominan polimorfismos si las variaciones son comunes (por definición ocurren en más del $1 \%$ de la población) y su impacto funcional es modesto o mínimo, pero supone un factor de riesgo cuando el organismo debe enfrentarse a un mayor esfuerzo metabólico o a un factor de riesgo ambiental. Varios polimorfismos, sin embargo, no tienen consecuencia funcional alguna. La suma de varios polimorfismos desfavorables pueden facilitar la aparición de una enfermedad (en este caso poligénica), cuya manifestación requiere, a menudo, la presencia de un marco ambiental propicio 2 .

Se han descrito numerosos alelos de riesgo y la lista de genes candidatos asociados al desarrollo de patologías cardiovasculares no cesa de ampliarse. Por ejemplo, los genes que codifican para la familia de los receptores $\beta 1, \beta 2$ y $ß 3$ adrenérgicos, son altamente polimórficos. Las variantes del receptor ß2-adrenérgico se han estudiado intensamente por su acción en la regulación de la contractilidad y ritmo cardíaco. Entre los polimorfismos dentro de la región codificante del gen de este receptor, se

Correspondencia: Dr. Sergio Lavandero

Facultad de Ciencias Químicas y Farmaceuticas

Facultad de Medicina, Universidad de Chile

Olivos 1007, Santiago - Chile

Teléfono: 838082

Correo Eléctronico:slavander@uchile.cl 
ha descrito que el polimorfismo Gln27 $\rightarrow$ Glu tiene un impacto funcional en los pacientes con insuficiencia cardíaca, los que al ser tratados con carvedilol mostraron una significativa mejoría en su función cardíaca ${ }^{3}$.

La terapia con inhibidores de la 3-hidroxi-3metilglutaril-coenzima $A$ reductasa para el tratamiento de la hipercolesterolemia, muestra variaciones interindividuales. El polimorfismo del gen de la 3 hidroxi-3-metilglutaril reductasa, un número variable de repeticiones en tándem (TTA)n, se ha relacionado con hipercolesterolemia y la enfermedad arterial coronaria 4 .

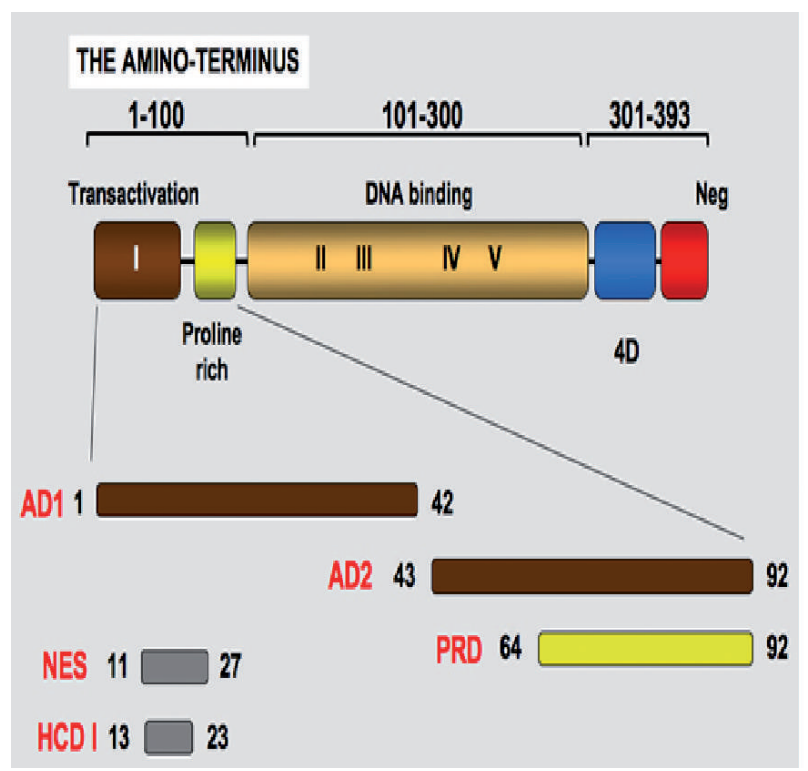

En el trabajo adjunto de Caamaño et al se estudia el polimorfismo Pro72Arg del gen TP53 en la enfermedad coronaria en una muestra de pacientes chilenos. El gen TP53 se ubica en el brazo corto del cromosoma 17. Contiene $22.000 \mathrm{pb}, 11$ exones que codifican para un mRNA de $2.2 \mathrm{~Kb}^{5}$. Este gen codifica para la proteína p53, siendo sus niveles muy bajos en las células normales dado que es activamente degradado. Sin embargo, los niveles de p53 se incrementan en las células expuestas a diferentes formas de estrés. El p53 es un factor transcripcional clave conocido como "guardián del genoma" dado que regula el ciclo celular y los procesos de senescencia, diferenciación y muerte celular.

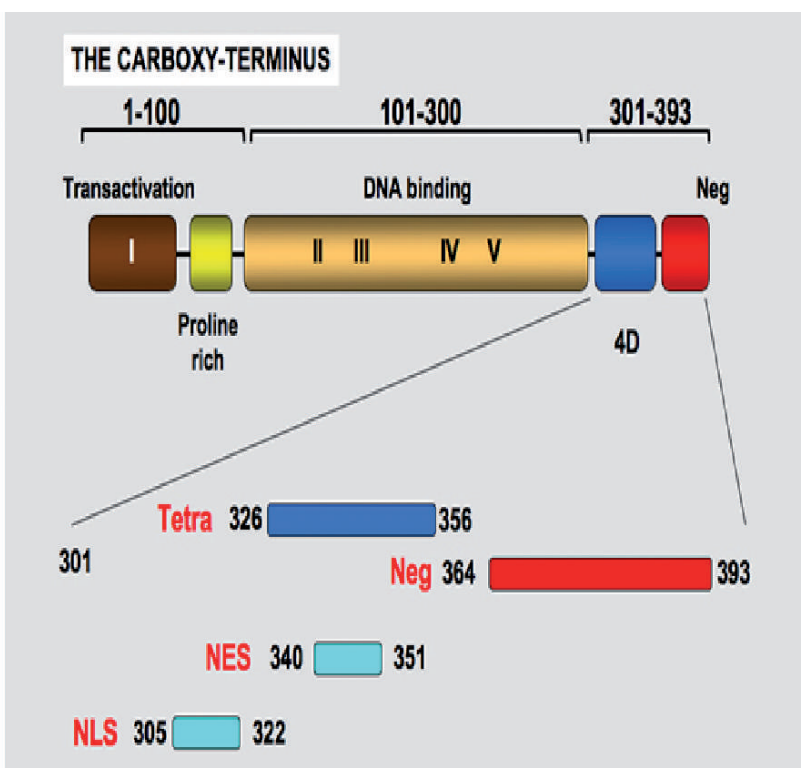

Figura 1: Estructura de p53. Región amino-terminal de p53. AD1: dominio de activación 1; AD2: dominio de activación 2; PRD: dominio rico en prolina; NES: dominio de exclusión nuclear; HCD I: dominio altamente conservado I. Región carboxilo-terminal de p53: tetra (4D): dominio de oligomerización; AD2: dominio de activación 2; NEG: dominio de regulación negativa; NES: dominio de exclusión nuclear; NLS: dominio de localización nuclear.

La proteína p53 contiene cinco dominios, cada uno con funciones específicas (Figura 1)5: la región amino-terminal contiene un dominio de transactivación y el sitio de unión para la proteína Mdm2. También contiene un Dominio Altamente Conservado I (HCD I). Esta región contiene series repetidas de residuos de prolina y otro dominio de transactivación. La región central contiene el dominio de unión a DNA, que es blanco del $90 \%$ de las mutaciones de p53 encontradas en cáncer. Además contiene los HCD II al V. Un dominio de oligomerización en el cual se encuentra la señal de exclusión nuclear. La región carboxilo-terminal contiene tres señales de localización nuclear (NSL) y un dominio a DNA inespecífico, el cual se une al DNA dañado.

Varios polimorfismos del gen TP53 se ha descrito en los últimos años. El polimorfismo de un simple nucleótido más estudiado es aquel localizado en el 
codón 72 (exón 4) del gen que resulta en un cambio de prolina (pro) a arginina (arg). Este polimorfismo se localiza en la región rica en prolina, la cual se requiere para la función proapoptótica de p53. La variante Arg72 muestra ser mejor inductor de apoptosis y represor de la transformación celular; en cambio, la variante Pro72 induce arresto del ciclo celular en mayor proporción que la variante Arg72 y también se ha mostrado inducir la transcripción de genes asociados a la reparación del DNA. iASSP, un regulador negativo de $\mathrm{p} 53$, inhibe preferentemente la variante Pro72. En contraste, la variante Arg72 escapa a esta regulación, por lo cual presenta un mayor potencial apoptótico, permitiendo una mejor respuesta a la quimioterapia y mayor sobrevida6.

La enfermedad arterial coronaria (EAC) es una enfermedad poligénica cuyas bases moleculares aún se encuentran bajo investigación 7 . El gen TP53 se ha relacionado a la etiología de la lesión aterosclerótica, ya que la proteína p53 se acumularía en este tejido, mediando la apoptosis de las células vasculares $^{8}$ y también la apoptosis en la placa aterosclerótica dependiendo de los niveles de expresión inducidos por daño al DNA9 ${ }^{9}$. Mutaciones o polimorfismos que se produzcan en este gen conducirá a una proteína con funcionalidad alterada que puede jugar un papel relevante en la patogénesis de esta enfermedad.

En el trabajo de Caamaño et al.10 se evaluó la posible asociación entre el polimorfismo Pro72Arg del gen TP53 y la enfermedad arterial coronaria en individuos chilenos. Este estudio analizó un grupo de pacientes con enfermedad arterial coronaria confirmada por angiografía y un grupo de control sin enfermedad coronaria demostrada por ausencia de angina y electrocardiograma. La genotipificación de la variante Pro72Arg del genTP53 se realizó utilizando la técnica PCR seguida del uso de enzima de restricción. El análisis de los datos mostró una significativa asociación entre enfermedad arterial coronaria y la presencia del alelo $\mathrm{R}$ (variante Arg72). La frecuencia del alelo $R$ fue mayor en los pacientes con enfermedad arterial coronaria que en los controles. Esta interesante asociación sugiere que esta variante genética podría ser un marcador genético para enfermedad arterial coronaria, sin embargo se requerirá el análisis de un mayor número de pacientes para confirmar este hallazgo.

\section{Referencias}

1. MedlinePlus Enciclopedia médica. Cardiopatía coronaria. Actualización 2009

2. NAVARRO-LÓPEZ F. Bases genéticas de la enfermedad coronaria. Rev. Esp. Cardiol. 55: 413-431, 2002.

3. TRONCOSO R, MORAGA F, CHIONG M, ROLDÁN J, BRAVO R, VALENZUELA R, et al. GIn27[ Gluß2-adrenergic receptor polymorphism in heart failure patients: differential clinical and oxidative response to carvedilol. Basic Clin Pharmacol Toxicol. 104: 374-378; 2009.

4. NORIEGA V, PENNANEN C, SÁNCHEZ MP, CHIONG M, LLANCAQUEO M, LAVANDERO $S$, et al. Influence of the HMG-CoA reductase (TTA)n repeat gene polymorphism on the effects of atorvastatin in coronary artery disease patients. Basic Clin Pharmacol Toxicol 104: 211-215; 2009.

5. The TP53 Web site. http://p53.free.fr/.

6. LIND $H$, EKSTROM PO, RYBERG D, SKAUG V, ANDREASSEN T, STANGELAND $L$, et al. Frequency of
TP53 mutations in relation to Arg72Pro genotypes in non small cell lung cancer. Cancer Epidemiol Biomarkers Prev. 16: 2077-2081; 2007.

7. WANG $Q$. Molecular genetics of coronary artery disease. Curr Opin Cardiol 20: 182-188; 2005.

8. AOKI M, MORISHITA R, MATSUSHITA H, NAKANO N, HAYASHI S, TOMITA N, et al. Serum deprivation-induced apoptosis accompanied by up-regulation of p53 and bax in human aortic vascular smooth muscle cells. Heart Vessels 1997; Suppl 12: 71-5.

9. MERCER J, BENNETT M. The role of $p 53$ in atherosclerosis. Cell Cycle 2006; 5: 1907-9.

10. CAAMAÑO J, SAAVEDRA N, JARAMILLO PC, LANAS C, LANAS F, SALAZAR LA. Polimorfismo Pro72Arg del gen TP53 se asocia a enfermedad coronaria en individuos chilenos. Rev Chil Cardiol 2009; 28: 151-157 